\title{
As configurações da Seguridade Social do Servidor Público Federal a partir da Constituição de 1988: uma primeira aproximação
}

THIAGo BaZI Brandão ${ }^{1}$

Resumo: Este texto tem por objetivo analisar as categorias e indicadores sobre os direitos sociais do Servidor Público Federal, grupo social que aqui é entendido como uma classe econômica, na acepção weberiana. Constata-se que os servidores públicos constituem um grupo social que tem mais acesso a benefícios e direitos sociais, em relação ao conjunto dos trabalhadores. Por outro lado, percebe-se que as normativas expedidas para a implantação da Seguridade Social do Servidor Público seguem a tendência do modelo gerencial de administrar a "coisa pública", em que pese o fato de privilegiar as melhorias na gestão do sistema, ao invés de trabalhar em prol da garantia e da ampliação dos direitos sociais dos servidores públicos.

Palavra-chave: seguridade social, servidor público federal, Constituição, Brasil, 1988.

The aspects of the Social Security of Federal Public Employees from the Constitution of 1988 on: a first approach

Abstract: This text has the objective of analytically examining and discussing some categories and indicators on the social rights of Federal Public Employees, which are hereby understood as an economic class, according to Weber. On one hand, we verified that public employees are a group with more access to benefits and social rights, in relation to other workers. On the other hand, we

Assistente Social e Mestre em Política Social pela UnB. 
noticed that the norms for the implantation of the Social Security of the Public Employee follow the tendency of the managerial model of the public administration, considering the fact of privileging the improvements in the administration of the system, instead of working in favor of the guarantee and the increase of public employee's social rights.

Keywords: social security, federal public employee, Constitution, Brazil, 1988.

\section{Políticas sociais e a burocracia estatal no Brasil}

A Constituição da República Federativa do Brasil de 1988 é conhecida como Constituição Cidadã, posto que assegurou, universalizou e ampliou direitos sociais. Estabeleceu ainda parâmetros para a regulamentação da legislação social que foram fundamentais para a elaboração do Estatuto da Criança e Adolescente, da Lei Orgânica da Assistência Social, da Lei de Diretrizes e Bases, da Lei Orgânica da Previdência Social, entre outras. Como conseqüência, a concepção de Seguridade Social ratificada na Carta Constitucional de 1988 propõe uma relação de cidadania e uma organização da política social na qual o Estado assume a primazia da administração e do financiamento do sistema com vista à redistribuição de renda, à eqüidade e à justiça social para toda a sociedade. Grosso modo, postula-se a radicalização da democracia por meio da intensificação da ação estatal e da participação da sociedade civil na concretização dos direitos sociais de forma universal. Apregoa-se, na legislação, uma cidadania universal em que Saúde, Previdência e Assistência Social são assumidas como dever do Estado e direito de todos os cidadãos. Pode-se dizer que a Constituição de 1988 consolidou, pelo menos na letra da lei, um Estado Social no Brasil.

É preciso considerar que a implantação dos preceitos constitucionais não tem sido bem-sucedida quando se fala em 
Seguridade Social, haja vista que o próprio texto constitucional sofreu inúmeras alterações no período pós-constituinte, especialmente na Política de Previdência Social em que os trabalhadores tiveram seus direitos reduzidos. A própria perspectiva de um orçamento único da Seguridade Social e de um Conselho da Seguridade Social foi sendo paulatinamente derruída pelos Governos que sucederam à Assembléia Nacional Constituinte de 1988. Estudos de Boschetti (2003) demonstram que, no campo da Assistência Social, as práticas institucionais clientelistas somadas à lógica do favor ainda são hegemônicas. Na Política de Saúde, a universalização do acesso e a eqüidade do atendimento às demandas propaladas na legislação constitucional e infraconstitucional lidam com a escassez de recursos orçamentários, descrédito quanto ao atendimento e com a propagação do seguro privado de saúde.

Nesse cenário, observa-se que há um segmento dos trabalhadores, membros da burocracia estatal, servidores ou empregados públicos que, pelo menos de maneira formal desde a promulgação do Estatuto dos Funcionários Públicos Civis da União (Lei no 1.711/1952), recebem tratamento diferenciado tanto em termos de salário, contrato e condições de trabalho quanto em relação à seguridade social. Na grande maioria dos Estados-Nação, os servidores públicos tiveram assegurados mais direitos e garantias em relação ao trabalho do que qualquer outro grupo de trabalhadores da iniciativa privada. Exemplo crasso disso é o instituto da estabilidade, fundamental para a segurança social do trabalhador, mas que só está claramente definido para os servidores públicos.

A Constituição de 1988, nos artigos 37 a 41, delineou o tratamento que seria dispensado pelo Estado aos seus agentes permanentes. Aos servidores, o acesso à Previdência Social é diferenciado, pois passaram a ser regidos por um Regime 
Próprio de Previdência Social (RPPS), e, posteriormente, foram regulamentadas essas prerrogativas constitucionais na Lei no 8.112/1990. Nessa lei estão previstas as formas de provimento, vacância, remoção, redistribuição e também os direitos e vantagens, o regime disciplinar e a seguridade social do servidor.

Em função dessa ótica distinta de atenção e tratamento para os trabalhadores do Estado, conformou-se um perfil específico de trabalhador. Marconi (2003), em estudo sobre o perfil da força de trabalho do setor público e privado, demonstra que os servidores públicos, geralmente, permanecem mais tempo nas organizações públicas, adquirem mais experiência no desempenho da função, mais capacitação específica na área de atuação e um senso de pertencimento à organização. Nesse sentido, possuem "maior acúmulo de capital humano específico relativo a uma determinada habilidade, isto é, maior conhecimento dos processos de trabalho que devem realizar. Em resumo, o perfil dos servidores públicos é qualitativamente melhor que o observado nos trabalhadores da iniciativa privada" (Marconi, 2003, p. 16). Em decorrência disso, a média salarial do serviço público é superior à da iniciativa privada. ${ }^{2}$

A "superioridade técnica" dos membros do aparato estatal é também justificada pela forma de ingresso, que exige a comprovação da qualificação requerida pelo cargo por meio de exames e concursos, pela perspectiva de uma carreira, pela exigência de uma formação, em geral, de nível superior, além da segurança no emprego garantida pelo instituto da estabilidade. Essas informações apresentam algumas características que distinguem os servidores públicos dos demais trabalhadores

2 Segundo Marconi, com base em dados do Boletim de Pessoal da Secretaria de Recursos Humanos do Ministério do Planejamento e do Censo Populacional do IBGE, o salário médio de um servidor público federal, em 1999, era de $R \$ 1598,00$ enquanto que um trabalhador da iniciativa privada percebia, em média, $R \$ 527,00$. 
e que, por isso, Ihes conferem um outro status e uma outra condição no contexto dos trabalhadores. É preciso considerar também que a categoria dos servidores e empregados públicos é bastante heterogênea em termos salariais, de condições de trabalho e da organização do trabalho. Coexistem grupos privilegiados pelos Governos como a intelligentsia estatal e a massa de servidores que desempenha funções operacionais parcamente remuneradas, atuando em condições de trabalho muitas vezes inadequadas para o desempenho da função e também nocivas à saúde.

Contudo, a posição privilegiada em relação aos trabalhadores da iniciativa privada não necessariamente garante melhores condições de vida e trabalho, bem como acesso aos direitos sociais. Assim, apesar de na Lei $\mathrm{n}^{\circ}$ 8.112/1990 constar um tópico sobre a seguridade social do servidor, ele ainda padece de atenção no sentido de ter regulamentadas as condições de sua manutenção no trabalho e de uma noção integrada de assistência social, saúde e previdência social expressas nos serviços sociais prestados. Desde 2003, com a criação da Mesa Nacional de Negociação Permanente, ${ }^{3}$ pela Secretaria de Recursos Humanos do Ministério do Planejamento, este tema foi incluído na agenda política do governo federal.

A proposta apresentada pelo governo consiste em regulamentar uma norma que garanta definitivamente um sistema de proteção social próprio para os servidores e empregados públicos. Podemos levantar duas questões acerca dessa proposta: ao implantar um sistema próprio de Seguridade Social do Servidor, o governo não estaria fracionando os interesses dos trabalhadores, reforçando a idéia da vigência

${ }_{3}$ O Regimento Institucional da Mesa Nacional de Negociação Permanente (MNNP), publicado e divulgado em 2003, encontra-se disponível em: <http://www.servidor.gov. br/mnnp/arq_down/reg_inst_mnnp.pdf>. 
de uma "casta" abastada no seio da classe trabalhadora? Podemos falar, também, que estaria se consolidando um conjunto de direitos para os servidores públicos?

Tentaremos discutir e analisar essas questões a partir de uma incursão no modelo atual e na proposta de normatização da Seguridade Social do servidor.

\section{Seguridade Social do servidor público}

As primeiras iniciativas com foco na constituição de um sistema de proteção social específico para os servidores podem ser encontradas nas prerrogativas do DASP presentes no Decreto no 11.101, de 1942: "VI. estudar os problemas de assistência e previdência social relativos aos servidores públicos".

A Lei nํ⒊373, de 1958, tratou do Plano de Assistência ao Funcionário e sua Família e criou o Instituto de Previdência e Assistência ao Servidor do Estado (Ipase). No Decreto no 200, de 1967, há tópicos que ressaltam a importância das políticas sociais dirigidas ao servidor público, como:

VIII - promover medidas visando ao bem-estar social dos servidores civis da União e ao aprimoramento das relações de trabalho (Brasil. Dasp, 1971, p. 7).

A política social para o servidor público no Brasil fora introduzida com o Estatuto dos Funcionários Públicos, aprovado na Lei 1.711, de 1952, e, depois, ratificada com a Lei no 8.112/1990, com a criação do Plano de Seguridade Social do Servidor. Além de instituir os preceitos burocráticos para provimento, progressão na carreira, remuneração e disciplina, também aborda os aspectos concernentes ao atendimento das necessidades sociais dos servidores, materializados nos 
benefícios, licenças, assistência à saúde, aposentadoria e pensões.

O instituto da estabilidade é certamente o aspecto mais relevante no que se refere à segurança social do funcionário, pois vincula-o à burocracia e garante a sua permanência, independentemente dos desígnios do "patrão". Já no Capítulo III da Lei $\mathrm{n}^{\circ}$ 1.711/1952, a estabilidade se apresentava como mecanismo de atrelamento e fidelidade do servidor ao Estado, tanto que, a sua demissão só estava prevista nos casos de sentença judicial transitada em julgado, e de processo administrativo que atestasse crime do servidor contra a administração pública. Esse direito tem sido paulatinamente transformado, haja vista que, depois da aprovação da Lei $\mathrm{n}$ 8.112, de 1990, e de suas sucessivas reformas, a possibilidade de o servidor público ser demitido passou a ser também por insuficiência de desempenho e por necessidade de cortes de gasto com pessoal do Estado (disposição contida na Lei de Responsabilidade Fiscal - Lei Complementar oㅜ 101/2000). Isso implica a possibilidade de perda de vínculo do funcionário com o cargo, e logo, a flexibilidade de um dos direitos fundantes da relação entre o funcionário e o Estado.

Como parte do atendimento às situações de contingência social do funcionário e dos seus familiares, a Lei oㅡ 8.112/1990 assegura-lhe o direito à licença para tratamento de saúde (arts. 202-206), por motivo de doença em pessoa da família (art. 83), para repouso à gestante (art. 207), para serviço militar obrigatório, para o trato de interesses particulares, por motivo de afastamento do cônjuge, funcionário civil ou militar, em caráter especial (art. 81). Se compararmos esses benefícios com os recebidos por um trabalhador formalizado vinculado a uma empresa privada, poderemos perceber a distância entre os direitos do servidor público e os do trabalhador da iniciativa privada, sem falar no enorme contingente de 
trabalhadores informais que têm acesso restrito aos direito sociais e trabalhistas. Como mostraram Campos, Nasser e Pereira (2002), os chamados benefícios eventuais, contidos na Lei Orgânica da Assistência Social (LOAS), ainda não estão regulamentados, o que impede a previsão orçamentária de recursos, bem como a definição dos tipos de benefícios que seriam concedidos ao cidadão submetido a certas situações de contingência social. O próprio auxílio-doença, que visa resguardar o trabalhador da iniciativa privada nas situações de enfermidade, é questionado pelos empregadores que coagem os funcionários licenciados, em alguns casos, com ameaças de demissão, e pelo próprio Instituto Nacional do Seguro Social que, correntemente, apresenta argumentos "enevoados" sobre o déficit da previdência, acompanhados das propostas de aumento no crivo da concessão das licenças e pensões.

A Lei no 8.112/1990, no seu capítulo VI, apresenta a "Seguridade Social do Servidor" e estabelece os aspectos constituintes do Plano de Seguridade Social para o servidor e seus dependentes legais ${ }^{4}$ (art.183-185). O primeiro critério de participação nesse sistema é a contribuição ao plano. A lógica securitária é determinante, porquanto os direitos estão vinculados à contribuição do servidor. Ressalte-se que a abrangência do Plano não se restringe aos benefícios previdenciários, pois este é um critério de acesso a outras licenças, benefícios, a assistência à saúde e assistência social.

4 De acordo com a Lei no 8.112/1990, são considerados dependentes legais o cônjuge ou a pessoa separada judicialmente, o companheiro ou companheira designados que comprovem união estável como entidade familiar, a mãe e o pai que comprovem dependência econômica do servidor; a pessoa designada maior de 60 anos e a pessoa portadora de deficiência que vivam sob a dependência econômica do servidor, além dos filhos ou enteados até 21 anos de idade, ou, se inválidos, enquanto durar a invalidez. 
O orçamento da Seguridade Social do Servidor é composto pela contribuição dos servidores e pelo recurso destinado pelo Estado à Previdência Social do Servidor Público. O financiamento do Plano é progressivo em termos absolutos, ou seja, o percentual pago é o mesmo, mas a quantia repassada varia conforme a remuneração. $O$ gasto é distributivo quando pensamos na aposentadoria e nas licenças, pois quem contribui mais receberá, por sua vez, a maior quantia de recursos; já com relação aos benefícios assistenciais (auxílio pré-escolar, auxílio alimentação e auxílio transporte), o atendimento é igualitário e independe da proporção de recursos dispensados para a contribuição.

O Plano de Seguridade Social do Servidor se propõe a atender às necessidades sociais dos servidores e dos seus respectivos familiares, dependentes legais. O Plano assemelhase a um sistema de proteção social corporativo, em que pese o fato de ser restrito a um grupo dos trabalhadores vinculados à burocracia estatal e, que, por isso, tem acesso a direitos exclusivos. Esse dado somado aos principais caracteres da configuração da seguridade social do servidor nos permite dizer que a burocracia estatal brasileira constitui-se em uma classe, na definição weberiana, diferenciada do conjunto dos trabalhadores.

No artigo 185 da referida lei são identificados os benefícios a que os servidores e seus familiares têm acesso. Podemos classificar os benefícios em três grupos: o previdenciário, que prevê a aposentadoria, as pensões, os auxílios natalidade, funeral, reclusão; o da saúde, que contempla a assistência à saúde, as licenças para tratamento de saúde, e os acidentes em serviço; e o da garantia de condições de trabalho adequadas. 
O direito à aposentadoria, que acompanha os membros da burocracia desde suas primeiras configurações históricas, foi reconhecido no Brasil com o Estatuto dos Funcionários Públicos e regulamentado na Lei no 3.373/1958, e depois transformado na Lei oㅜ 8.112/1990.

Observa-se, no tocante à previdência social, que as emendas à Constituição de 1988, embasadas pelo discurso governamental do déficit da previdência social e dos prejuízos dela decorrentes ao erário público, provocaram um aumento no tempo de contribuição e de permanência do servidor no exercício do trabalho. A aposentadoria foi o direito que sofreu mais alterações desde a homologação da Lei oㅜ 8.112, em 1990.

A primeira reforma foi realizada em 1998, com a aprovação da Emenda Constitucional no 20, seguida da Emenda no 41, aprovada em 2003, e da Emenda no 47, a chamada PEC Paralela, aprovada em 2005, que estabeleceu regras de transição distintas aos servidores que ingressaram no serviço público antes das reformas. A Emenda no 20 estabeleceu idade mínima para a aposentadoria e tempo de permanência no serviço público, enquanto que a Emenda ํo 41 aumentou os critérios para a aposentadoria e o tempo mínimo no serviço público de 10 para 20 anos. Além disso, a base de cálculo para a remuneração na aposentadoria deixou de ser a remuneração do cargo efetivo para ser a média dos $80 \%$ maiores salários, isso implica que o servidor aposentado terá o seu provento de aposentadoria inferior ao último recebido na ativa. Já a Emenda no 47 restabeleceu a paridade entre ativos e inativos, integralidade dos proventos, isenção de contribuição para os portadores de doença grave especificada em lei, e também criou mecanismos de transição no tocante à vinculação da idade e do tempo de contribuição para aqueles servidores que estão na ativa. 
Atualmente, o direito à aposentadoria no serviço público está subdividido em três formas de aposentadoria, a saber: por invalidez permanente nos casos de acidente em serviço, doença ou moléstia profissional; a compulsória, que se dá quando o servidor completa 70 anos de idade; e a voluntária, que se dá com proventos integrais para homens com 35 anos de tempo de contribuição e 60 anos de idade e para mulheres com 30 anos de tempo de contribuição e 55 anos de idade, já com proventos proporcionais para homens com 65 anos de idade e mulheres com 60 anos de idade. Se compararmos com o cenário que antes vigorava, houve um aumento no tempo de contribuição e na idade mínima para se aposentar (art. 186 da Lei $n$ - 8.112/1990). Além disso, foram incluídos outros requisitos para a aposentadoria como um tempo mínimo de permanência no serviço público (20 anos), no órgão ao qual está vinculado (10 anos) e no cargo (5 anos) que está ocupando quando da aposentadoria.

É interessante frisar que no parágrafo único do art. 186 da Lei $\mathrm{n} \times 8.112$ fica garantida a paridade entre ativos e inativos. Em razão dessa prerrogativa legal, os governos têm optado por conceder aumentos salariais aos servidores por meio de gratificações de desempenho ou mérito, de forma a não estender os reajustes para os servidores ativos aos aposentados. ${ }^{5}$ Está prevista a perda da integralidade, ou seja, a redução do teto da remuneração da aposentadoria nos patamares do Regime Geral de Previdência Social, mas esta disposição precisa ser regulamentada com a criação de um fundo complementar de previdência social para os servidores públicos, o que, de

5 Conforme a edição do jornal Correio Braziliense, de 30 de novembro de 2006, em junho de 2006, o governo federal expediu uma série de aumentos na remuneração dos servidores públicos. O aumento concedido foi variado de acordo com o tempo de serviço, cargo ocupado e, principalmente, se o servidor está em exercício ou aposentado. O aumento salarial foi "legal" (não rompeu com a paridade), porquanto se baseou em gratificações produtivistas e de desempenho que desconsideram os aposentados. 
certa forma, restringiria o acesso à aposentadoria integral e incentivaria a migração dos servidores para os Planos Privados de Previdência Complementar. Destaca-se também, o fato de os servidores aposentados serem obrigados a contribuir para o Plano de Seguridade Social do Servidor quando receberem a aposentadoria ou a pensão com valor superior ao teto do RGPS.

Seguindo a apresentação e a análise dos benefícios a que os servidores públicos federais têm acesso, existe um grupo significativo de auxílios e licenças assegurados em lei aos funcionários do Estado. Dentre esses, há o auxílionatalidade que visa assistir o servidor ou cônjuge nos casos de nascimento de filho(a) pela concessão do valor do menor salário da administração pública (art.196 da Lei no 8.112/1990). No caso de morte do servidor, os dependentes legais têm direito a percepção do auxílio-funeral (art. 226 da Lei no 8.112/1990). Também aos dependentes legais cabe o direito à pensão vitalícia ou temporária (arts. 215-216 da Lei no 8.112/1990). Como no caso da aposentadoria, as pensões têm garantida a paridade de reajustes com os ativos, mas também sofreram as limitações dos aumentos recentes (2006) concedidos com base em gratificações de produtividade, quer dizer, de atividade. Ademais, depois da Emenda Constitucional no 41, o valor máximo da pensão passou a ser o equivalente ao valor do teto do regime geral da previdência somado a $70 \%$ do valor restante.

Para a família do servidor ativo que for preso, é possível acessar o auxílio-reclusão que equivale a dois terços da remuneração, quando afastado por motivo de prisão, em flagrante ou preventiva, ou à metade da remuneração, durante o afastamento, em virtude de condenação, por sentença 
definitiva, considerando a pena que não determine a perda de cargo (art. 229 da Lei 8112/1990).

Os servidores acometidos de doença têm direito à licença para tratamento de saúde. Para isso devem ser submetidos à perícia médica para a avaliação da condição laborativa, bem como para a homologação da licença (art. 202 da Lei no 8.112/1990).

As servidoras têm acesso à licença-gestante de 120 dias, ou 30 dias no caso de aborto ou bebe natimorto, sendo que, em ambos os casos, as servidoras devem passar por perícia médica (art. 207 da Lei no 8.112/1990). A servidora que adotar uma criança tem direito de receber a licença-adotante, que, nos casos de crianças de até um ano de idade, são 90 dias de licença remunerada, e quando a criança tem mais de um ano de idade são 30 dias (art. 207 da Lei oㅜ 8.112/1990). O servidor tem direito à licença-paternidade de cinco dias consecutivos e a servidora, para amamentar o filho de até seis meses de idade, tem direito, durante a jornada de trabalho, a uma hora de descanso, que poderá ser parcelada em dois períodos de meia hora (arts. 208-209 da Lei oㅡ 8.112/1990).

O servidor tem também direito à licença por acidente em serviço com remuneração integral, podendo, caso necessite de tratamento especializado inexistente na rede pública, ser tratado em instituições privadas a conta de recursos públicos (arts. 211-213 da Lei no 8.112/1990).

Além das licenças, o servidor tem direito à assistência à saúde, que compreende o acesso ao Sistema Único de Saúde, aos serviços prestados diretamente pelo órgão ou entidade ao qual estiver vinculado (a maior parte dos órgãos públicos possui uma unidade de saúde própria), ou por meio de convênio ou contrato com planos ou seguros privados de assistência à 
saúde, que exige a adesão e o pagamento adicional do servidor e de seus dependentes ou pensionistas, sendo que a outra parte do custeio é proveniente de recursos da União.

Nesse sentido, há situações em que o servidor pode ter acesso ao SUS, ao serviço de assistência à saúde do órgão e à rede de atendimento do seguro privado de saúde, combinando direitos exclusivos com universais. Soma-se a isso o fato de que a lógica da privatização dos serviços de saúde é incitada no próprio seio da administração pública responsável pela execução dos serviços públicos de saúde a toda a população, pois são criadas as condições para a contratação de serviços de saúde prestados pela iniciativa privada e concedidos benefícios (reembolsos e contrapartidas) em alguns órgãos para os servidores aderirem ao Plano de Saúde.

Além dos direitos garantidos na Lei nº 8.112/1990, os servidores públicos têm acesso a mais benefícios, previstos em outras normativas, denominados de assistenciais, a saber: auxílios alimentação, transporte e pré-escolar. O auxílioalimentação, previsto na Lei $n \times$ 9.527/1997, e regulamentado no Decreto no 3.887/2001, garante ao servidor em exercício recursos, na forma de pecúnia e de caráter indenizatório, para custear uma refeição diária. O benefício é pago por dia trabalhado e não pode ser incorporado aos proventos e nem acumulado mais de um auxílio-alimentação, em função da ocupação de dois cargos. O auxílio-transporte, regulamentado pelo Decreto no 2.880/1998, supre o custo do servidor do translado de casa para o trabalho e vice-versa, conforme o valor das tarifas de transporte, excetuando-se os deslocamentos realizados em intervalos para repouso ou alimentação, durante a jornada de trabalho, e aqueles efetuados com transporte próprio. A principal diferença do auxílio-transporte em relação ao auxílio-alimentação é a exigência de contrapartida do servidor de $6 \%$ de sua remuneração. 
Acrescenta-se a esses, o auxílio pré-escolar, regulamentado pelo Decreto $n^{\circ}$ 977/1993, que se caracteriza por ser uma transferência de recursos do Estado destinada aos servidores com filhos (ou enteados, ou criança que viva sob a tutela do servidor) menores de seis anos de idade ou filhos de qualquer idade com doença incapacitante para o trabalho, visando garantir condições aos dependentes legais de acesso à educação infantil, bem como ao seu desenvolvimento biopsicossocial. O auxílio pré-escolar pode ser convertido na prestação dos serviços de creche no órgão ao qual o servidor estiver vinculado, como ocorre no Ministério da Saúde, que possui uma creche para atender os filhos dos servidores do órgão.

De toda a forma, a rede de seguridade social do servidor público, provida exclusivamente pelo Estado, confere a esse grupo de trabalhadores um status diferenciado em relação aos demais trabalhadores. Os servidores públicos não estão à mercê dos desígnios dos patrões, em virtude das garantias previstas em lei. Primeiro, em função da garantia da estabilidade (apesar da flexibilização desse direito). Em segundo lugar, pela garantia legal de proteção nos casos de contingências sociais relacionadas a problemas de saúde ou outras questões, como problemas familiares e de ordem pessoal, sem o risco de perda de emprego. Em terceiro lugar, pela existência dos benefícios sociais que, a despeito da defasagem monetária, estão garantidos a todos os servidores públicos que o solicitarem (e atenderem os requisitos, no caso do auxílio-creche), ou seja, são universais. Por fim, é indispensável destacar os direitos exclusivos decorrentes da sua condição de trabalhadores do Estado e podem também gozar o direito à saúde e à educação pública, bem como a outras políticas públicas gestadas pelo Estado para todos os cidadãos. Isso permite dizer que os 
servidores públicos são favorecidos, no que tange à garantia de direitos de cidadania, pois podem ter acesso aos direitos exclusivos e aos universais. Portanto, apesar das reformas constitucionais, os servidores públicos ainda representam uma classe diferenciada do conjunto dos trabalhadores em se tratando do acesso aos direitos sociais.

\section{Proposta de Regulamentação da Seguridade Social do Servidor Público Federal}

O governo federal, no bojo do pacote de reforma da previdência social, trouxe uma proposta de criação de um marco regulatório para a seguridade social do servidor. Para isso, criou em 2003 uma unidade administrativa, a Coordenação-Geral de Seguridade Social e Benefícios do Servidor Público, ligada a Secretaria de Recursos Humanos (SRH) do Ministério do Planejamento, Orçamento e Gestão (MPOG) para capitanear essa proposta. Uma das primeiras medidas tomadas foi a criação da Mesa Nacional de Negociação Permanente (MNNP) que tinha como objetivos: a discussão colegiada com a participação dos órgãos representativos dos servidores públicos acerca das questões de relações de trabalho entre Administração Pública e Servidor Público, a negociação de pauta de reivindicações e das questões relativas à gestão pública. Foram criados assim grupos de discussão sobre temas como: a questão salarial e de carreiras, a questão previdenciária descolada de outro grupo de discussão relacionado à criação de uma norma regulamentadora da Seguridade Social do Servidor.

O primeiro documento com a proposta de Norma de Seguridade Social do Servidor foi apresentado em 2003, mas não foi aprovado, e encontra-se na sua $18^{a}$ versão. Todavia, os atores governamentais optaram por extrair alguns itens dessa proposta para a regulamentação de algumas questões 
prioritárias para o governo, como a instituição de um manual de procedimentos operacionais a serem implantados na concessão de licenças e benefícios.

A argumentação apresentada nos documentos oficiais versa explicitamente sobre a proposição de

uma política de seguridade social uniforme para todos os servidores públicos civis federais, fazendo com que seus vértices: assistência social (pagamento de auxílios, como alimentação, creche, transporte), saúde suplementar, saúde ocupacional e previdência, tivessem um norteador comum, privilegiando uma gestão eficiente e valorizando o servidor (Brasil. MPOG, 2006a, p. 1).

Tendo como beneficiários os servidores públicos - ocupantes de cargos efetivos, de cargos comissionados - e os empregados públicos vinculados aos órgãos e entidades do Poder Executivo Federal, essa Norma, para os empregados públicos, é concorrente da legislação trabalhista (Consolidação das Leis do Trabalho - CLT) em vigor. Isso implica dizer que essa política atende aproximadamente 1.827 .900 pessoas. ${ }^{6}$ Mas, o seu alcance é diferenciado para os empregados públicos, pois o direito à aposentadoria é vinculado ao RGPS. A Política adota como princípios e diretrizes:

a) universalidade da cobertura e do atendimento;

b) uniformidade e equivalência dos benefícios e serviços aos servidores públicos federais;

c) seletividade e distributividade na prestação dos benefícios e serviços;

d) solidariedade na forma de participação no custeio;

6 Dado colhido no Boletim Estatístico de Pessoal no 122, do Ministério do Planejamento, Orçamento e Gestão, de junho de 2006. 
e) caráter democrático da gestão administrativa com a participação dos servidores públicos e aposentados". (Brasil. MPOG, 2006b, p.1).

Esses princípios trazem avanços no que se refere à política social para o servidor público, como a inclusão da participação dos servidores na gestão da política. Todavia, das medidas até agora adotadas com relação à Seguridade Social do Servidor, a participação das entidades representativas dos servidores tem se dado apenas no plano formal. $O$ ator político (governo) tem sido hegemônico nas ações implantadas, pois, mesmo com a resistência de servidores de alguns Estados da Federação quanto à implantação do Sistema de Saúde Ocupacional do Servidor Público (SISOSP), a proposta foi regulamentada no Decreto n 5.961 , de 13 de novembro de 2006.

Além disso, a questão da universalidade de cobertura e atendimento e da uniformidade dos benefícios é contradita pelas propostas seguintes apresentadas no mesmo documento, principalmente a ratificação da política de saúde suplementar que limita a sua cobertura àqueles servidores que têm condições de comprar o serviço. Não aparece nos princípios e nem nas diretrizes, mas, implicitamente, notamos a perspectiva da mercantilização dos serviços sociais.

A proposta de eficiência na gestão pública está presente em todos os documentos, mas vem acompanhada dos discursos da implantação da proteção social e da valorização do servidor. A crítica exposta no documento atinge as disposições constitucionais que enxergam no servidor público apenas um instrumento e não um sujeito de direitos, o que, dispensaria um tratamento diferenciado no que se refere à política de seguridade social do servidor. A proposta veiculada pelos meios de comunicação governamentais $e$ 
propalada nos encontros das entidades de recursos humanos da administração pública federal abusa do discurso a favor do servidor público. No entanto, as propostas até agora aprovadas por essa equipe governamental têm primado pela redução dos direitos e pelo aprimoramento do controle dos gastos com pessoal e dado pouca atenção para a valorização do servidor; em outros termos, a racionalidade e a eficiência da organização sobrepujam a lógica de atenção ao servidor. Portanto, a idéia de valorização e de garantia de direitos dos servidores apresenta-se mais como discurso ídeo-político do que como prática de políticas públicas.

A Secretaria de Recursos Humanos do MPOG realizou uma pesquisa comparativa dos benefícios e licenças dos servidores públicos e dos trabalhadores ligados ao regime geral de previdência em 2004. O cenário apresentado sinaliza para uma situação de irregularidade na gestão da seguridade social do servidor. A apropriação desses dados seguiu a perspectiva de empreender mudanças na gestão da seguridade social do servidor, especialmente, na questão da regulação da saúde do servidor, ou seja, da concessão de licenças e auxílios, quando poderia haver estudos e ações que explorassem uma intervenção efetiva na organização e nas condições de trabalho no serviço público, tendo em vista que os dados apresentados demonstram a ocorrência de um fenômeno coletivo que deve ter causalidades sociais, por isso não bastam apenas soluções técnicas de melhoria da gestão dos processos da seguridade social.

É interessante constatar que as diferenças apresentadas nesta pesquisa entre ambos os regimes estão intimamente associadas à questão previdenciária, pois os gastos com saúde do servidor, tornam-se gastos com aposentadoria por invalidez, com licenças, entre outros. Observa-se a ênfase no aspecto financeiro como justificativa que fundamenta essa política. 
Informe veiculado no sítio eletrônico do servidor público, intitulado de Aposentadoria por Invalidez Preocupa a Administração Pública Federal, revela a possibilidade de revisão de $73 \%$ das aposentadorias por invalidez. E aponta como reposta a essa situação a criação do Sistema Integrado de Saúde Ocupacional do Servidor Público Federal (SISOSP), na perspectiva de controlar o acesso às aposentadorias $\mathrm{e}$ licenças do servidor. Para isso, o SISOSP inicia-se como um projeto piloto no DF, com recursos iniciais aprovados na lei orçamentária para 2007 , da ordem de $\mathrm{R} \$ 10$ milhões. Portanto, uma das principais funções do sistema criado é reduzir os gastos com os direitos sociais dos servidores públicos federais.

As necessidades sociais dos servidores públicos são percebidas tão-somente relacionadas à questão das condições de saúde, ao passo que aspectos referentes a condições e organização do trabalho, como causadores dos problemas de saúde, são tangenciados nesse debate que prioriza o enfoque sobre a gestão desses serviços. Questões como assédio moral ou sexual, estresse, trabalho em condições insalubres, ausência de uma política clara de segurança no trabalho e necessidades sociais intermediárias (Pereira, 2000) não foram submetidas a uma análise radical, porquanto forçosamente a razão dessa situações é atribuída apenas à má gestão, argumento típico do ideário gerencial que busca a melhoria da gestão via alcance de resultados que possam ser quantitativamente e financeiramente medidos.

Desse modo, a resposta governamental a esse cenário resultou na publicação da Portaria no 1.675, de 6 outubro de 2006, e no Decreto oㅡ 5.961, de 13 de novembro de 2006, que apresentam como foco a organização do sistema de concessão de licenças para tratamento de saúde, acompanhamento de parente enfermo, aposentadoria por invalidez, revisão de aposentadoria, reversão, entre outras ações que compõe a 
Perícia Médica. Estão detalhados na Portaria Ministerial todos os procedimentos que a equipe que trabalha com a Vigilância a Saúde do Trabalhador, Vigilância Ambiental às Condições de Trabalho e com Perícia Médica deve adotar para garantir a aplicação da norma estabelecida e, logo, o combate ao descompasso e à concessão de licenças irregulares. Em última instância, podemos afirmar que se tenciona controlar os processos e a própria saúde dos servidores públicos em favor da redução de despesas com o acompanhamento, tratamento e benefícios.

Com a mesma orientação ídeo-política foi publicada a Portaria no 1.983/2007, do Ministério do Planejamento, que regulamentou a cobertura da saúde suplementar para os servidores. Essa normativa limitou o acesso aos serviços, deixando de fora da cobertura a ajuda de custo para órteses e próteses, a internação em quartos, e os transplantes ficaram limitados a rins, córneas, fígado e coração. Essa proposta, que já vigora no Ministério da Educação, terá vigência a partir de 2008, quando os filhos que têm como dependentes legais os pais terão de pagar o valor total do custo por dependente (sem contrapartida do governo) para manter o atendimento. A justificação do governo para essa proposta segue a linha da ampliação do acesso à saúde suplementar, pela via da redução das garantias implícitas ao direito. Segundo o coordenadorgeral de Seguridade Social e Benefícios do Servidor, "a portaria não tirou o direito de pais e mães ficarem no plano, mas o governo não tem condições de pagar. Além disso, os preços ficaram mais baixos" (Grossmann, 2007).

Percebe-se, nessa normativa, o interesse em lidar com o direito à saúde sob uma ótica mercantil e privatista, na qual o direito é percebido como produto, e o acesso a ele é negociado a partir da redução de outras garantias. Sendo assim, sorrateiramente, publicando portarias ministeriais, 0 
governo está construindo essa nova feição da seguridade social do servidor público federal.

Podemos questionar o seguinte: em que medida essas propostas seguem o receituário da administração pública gerencial postulada pelo então ministro da Administração e Reforma do Estado, Luís Carlos Bresser Pereira? A proposta de Reforma de Estado tinha como metas a redução da máquina pública, cortes de pessoal, terceirização, privatização e publicização da ação estatal. Sustentavam essa proposta argumentos que apontavam a ineficiência da prestação de serviços do Estado, o gigantismo da administração pública e o gasto excessivo com pessoal que repercutia nas políticas econômicas engendradas pelo governo. As diretrizes dessa política de reforma do Estado estão ancoradas nos conceitos baseados na lógica da gestão de organizações privadas com fins lucrativos, como produtividade, avaliação de desempenho, accountability (busca por resultados) e governança (eficiência na gestão), que vão sendo incorporados no vocabulário e nas políticas de gestão de pessoas da burocracia estatal brasileira. Em suma, a intenção externada é a de aprimorar a gestão pública.

Ora, a política de seguridade social para os servidores públicos federais, executada desde 2003, não está seguindo essas mesmas diretrizes, ou seja, o objetivo explícito não é o de prover governança (qualidade e eficiência na gestão) à política de seguridade social do servidor? Ou existem propostas de ampliação de direitos?

Lidamos com o dilema de que a regulamentação da Seguridade Social do Servidor pode trazer uma referência para a política social a ele destinada, mas, ao mesmo, pode também gestar mecanismos de controle da força de trabalho e redução paulatina dos direitos, os quais se fundam, paradoxalmente, no discurso da valorização do servidor. 


\section{Considerações finais}

Essa breve incursão realizada nas políticas sociais direcionadas aos servidores da administração pública federal traz consigo algumas características da própria formação da política social no Brasil, bem como as tendências que se colocam no cenário atual. A tentativa de apresentar o corpo dos servidores públicos como uma classe, na definição weberiana, distinta das outras classes de trabalhadores, em função do escopo de garantias legais relativas à proteção e à segurança social, é certamente uma das contribuições teóricas trazidas para esse debate, que ainda precisa ser mais aprofundado.

As análises apresentadas ainda são iniciais e inconclusas, porquanto lidamos apenas com os aspectos normativos e com o substrato teórico-político presente nessas ações. As pesquisas devem avançar no estudo dessa política, na perspectiva da real participação dos trabalhadores no processo decisório, bem como da participação das categorias profissionais, além da necessidade de um estudo mais detalhado sobre o financiamento e o gasto dessas políticas.

É fato que a burocracia estatal tem sido debatida nos estudos das políticas públicas como uma ferramenta, ou melhor, como um ator que influencia a operacionalização das políticas, mas este texto tentou demonstrar o quão relevante é refletir sobre as políticas geradas para atender àqueles que as operam. Assim, além de representar um grupo, se quisermos dizer, uma classe significativa em termos de contingente de trabalhadores e, logo, como sujeito de direitos, ela tem um papel essencial na gestão das políticas. Por isso, vamos notar, também, os rebatimentos do tipo de política social dirigida aos servidores públicos na prestação dos serviços sociais a toda a população. 


\section{Referências bibliográficas}

BOSCHETTI, Ivanete. Assistência social no Brasil: um direito entre originalidade e conservadorismo. 2. ed. Brasília: Gesst/SER/UnB, 2003.

BOSCHETTI, Ivanete. Dimensões, categorias e indicadores para análise e avaliação de políticas sociais. Brasília, 2006.

BRASIL. Constituição [da] República Federativa do Brasil. Brasília: Senado Federal, 1988.

. Departamento Administrativo do Serviço Público. O Dasp e a política de pessoal: documentação básica. Brasília, 1971.

. Presidência da República. Lei no 1.711 de 1952. Estatuto dos Funcionários Públicos. Diário Oficial da União, 1ํonov. 1952.

. Presidência da República. Lei no 8.112 de 1990, que dispõe sobre o funcionalismo público. Diário Oficial da União, 12 dez. 1990.

Presidência da República. Decreto № 977 de 1993 que regulamenta a assistência pré-escolar destinada aos dependentes dos servidores da Administração Pública Federal direta, autárquica e fundacional. Diário Oficial da União, 11 nov. 1993.

. Presidência da República. Decreto no 2.880 de 1998 que regulamenta o auxílio transporte destinado aos servidores da Administração Pública Federal direta, autárquica e fundacional. Diário Oficial da União, 16 dez. 1998.

Presidência da República. Decreto № 3.887 de 2001 que regulamenta o auxílio alimentação destinado aos servidores da Administração Pública Federal direta, autárquica e fundacional. Diário Oficial da União, 17 ago. 2001.

. Presidência da República. Decreto no 5.961 de 2006 que institui - Sistema Integrado de Saúde Ocupacional do Servidor Público Federal - SISOSP. Diário Oficial da União, 14 nov. 2006.

. Ministério do Planejamento, Orçamento e Gestão MPOG, Secretaria de Recursos Humanos. Portaria № 1.675, de 6 de outubro de 2006 que dispõe que dispõe sobre os procedimentos relativos a política de saúde para servidor. Brasília, Diário Oficial da União, Brasília, 10 out. 2006a. 
BRASIL. Norma Regulamentadora da Seguridade Social do Servidor Público. 18 ${ }^{\underline{a}}$ versão. Disponível em: <http://www.servidor.gov. $\mathrm{br} / \mathrm{seg}$ _social/arq_down/norma_regulamentadora.pdf>. Acesso em: 8 set. $2006 b$.

BRASIL. Boletim Estatístico de Pessoal, n. 122, junho, 2006. Disponível em:<http://www.servidor.gov.br/publicacao/boletim_estatistico/bol_ estatistico_06/Bol122_Jun2006.pdf>. Acesso em: 8 set. 2006c.

CAMPOS, Sônia Maria Arcos; NASSER, leda Rebelo; PEREIRA, Potyara Amazoneida Pereira. Os percalços dos benefícios eventuais regidos pela LOAS. Cadernos do CEAM, Brasília, v. 3, n. 11, out. 2002.

COIMBRA, M. A. Será que o marxismo responde à pergunta de como surgem as políticas sociais?. In: ABRANCHES, S. H. et al. Política social e combate à pobreza. Rio de janeiro: Jorge Zahar Editor, 1987. p. 105-126.

CORREIO BRAZILIENSE [Jornal], Brasília, 30 nov. 2006; 8 ago. 2007.

FAORO, Raymundo. Os donos do poder: formação do patronato político brasileiro. 10. ed. São Paulo: Globo; Publifolha, 2000.

MARCONI, Nelson. A evolução do perfil da força de trabalho e das remunerações nos setores público e privado ao longo da década de 1990. Revista do Serviço Público v. 54, n. 1, jan./mar. 2003.

PEREIRA, Potyara Amazoneida Pereira. Necessidades humanas: subsídios à crítica dos mínimos sociais. São Paulo: Cortez, 2000.

WEBER, Max. Economia e Sociedade: fundamentos da sociologia compreensiva. Trad. Regis Barbosa e Karen Elsabe Barbosa, revisão técnica de Gabriel Cohn. 3.ed Brasília (DF): Editora da UnB, 1999. v.1.

. Economia e Sociedade: fundamentos da sociologia compreensiva. Trad. Regis Barbosa e Karen Elsabe Barbosa, revisão técnica de Gabriel Cohn. Brasília (DF): Editora da UnB, 2004. v. 2. 